\title{
ROLE OF CYP2E1-MEDIATED METABOLISM IN THE ACUTE AND VESTIBULAR TOXICITIES OF NINETEEN NITRILES IN THE MOUSE
}

Sandra Saldaña-Ruíz ${ }^{\mathrm{a}, \mathrm{b}}$, Carla Soler-Martín ${ }^{\mathrm{a}, \mathrm{b}}$, and Jordi Llorens ${ }^{\mathrm{a}, \mathrm{b}, 1}$

${ }^{a}$ Departament de Ciències Fisiològiques II, Universitat de Barcelona; ${ }^{b}$ Institut d'Investigació Biomèdica de Bellvitge (IDIBELL), ${ }^{\text {a,b }} 08907$ L'Hospitalet de Llobregat (Catalunya), Spain

${ }^{1}$ Corresponding author. Departament de Ciències Fisiològiques II, Universitat de Barcelona, Feixa Llarga s/n, 08907 L'Hospitalet de Llobregat (Catalunya), Spain. Tel.: 34-93-402 4277. FAX: 34-93-402 4268. E-mail: jllorens@ub.edu.

${ }^{a}$ Parts of this study were presented at the XII International Congress of Toxicology, IUTOX 2010, Barcelona (Catalunya), Spain, July 2010. 


\begin{abstract}
Allylnitrile, cis-crotononitrile, and 3,3'-iminodipropionitrile are known to cause vestibular toxicity in rodents, and evidence is available indicating that cis-2pentenenitrile shares this effect. We evaluated nineteen nitriles for vestibular toxicity in wild type (129S1) and CYP2E1-null mice, including all the above, several neurotoxic nitriles, and structurally similar nitriles. A new acute toxicity test protocol was developed to facilitate evaluation of the vestibular toxicity by a specific behavioral test battery at doses up to sub-lethal levels while using a limited number of animals. A mean number of $8.5 \pm 0.3$ animals per nitrile, strain and sex was necessary to obtain evidence of vestibular toxicity and optionally an estimation of the lethal dose. For several but not all nitriles, lethal doses significantly increased in CYP2E1-null mice. The protocol revealed the vestibular toxicity of five nitriles, including previously identified ototoxic compounds and one nitrile (trans-crotononitrile) known to have a different profile of neurotoxic effects in the rat. In all five cases, both sexes were affected and no decrease in susceptibility was apparent in CYP2E1-null mice respect to 129S1 mice. Fourteen nitriles caused no vestibular toxicity, including six nitriles tested in CYP2E1-null mice at doses significantly larger than the maximal doses that can be tested in wild type animals. We conclude that only a subset of low molecular weight nitriles is toxic to the vestibular system, that species-dependent differences exist in this vestibular toxicity, and that CYP2E1-mediated metabolism is not involved in this effect of nitriles although it has a role in the acute lethality of some of these compounds.
\end{abstract}

Keywords: Ototoxicity, Vestibular toxicity, Nitrile, Xenobiotic metabolism, CYP2E1, Lethality, Acute toxicity test protocol. 


\section{INTRODUCTION}

Nitriles are compounds containing cyano $(\mathrm{R}-\mathrm{CN})$ groups; they are common in crop plants and their use in the chemical and pharmaceutical industries is becoming increasingly frequent. Nitriles with large production volumes are used as solvents and chemical intermediates in a variety of processes, including the synthesis of plastics, nylons, and elastomers (DeVito, 2007). Among their major toxic effects are acute lethality, osteolathyrism and neurotoxicity, including sensory toxicity (DeVito, 1996; DeVito, 2007; Llorens et al., 2011). One significant target for several nitriles is the inner ear: degeneration of the vestibular and/or auditory hair cells has been reported in rodents exposed to 3,3'-iminodipropionitrile (IDPN) (Crofton and Knight, 1991; Llorens et al., 1993; Crofton et al., 1994; Llorens and Rodríguez-Farré, 1997; Seoane et al., 2001), allylnitrile (Balbuena and Llorens, 2001; Gagnaire et al., 2001), ciscrotononitrile (Balbuena and Llorens, 2003), racemic crotononitrile (Llorens et al., 1998; Gagnaire et al., 2001) and cis-2-pentenenitrile (Gagnaire et al., 2001).

Cyanide release by nitrile metabolism was identified as a major cause of the acute lethality effect that characterizes many nitriles (Willhite and Smith, 1981; Tanii and Hashimoto, 1984), and a major role was hypothesized for the alcohol/acetoneinducible isoform of the P450 cytochrome (CYP2E1) in this metabolism (Lewis et al., 1994). Ensuing studies demonstrated that the CYP2E1 enzyme metabolizes a number of low molecular weight alkyl nitriles (Ghanayem et al., 1999) and is responsible for the initial metabolism of acrylonitrile leading to cyanide release (Wang et al., 2002; Chanas et al., 2003; El Hadri et al., 2005). However, the role of this or other metabolic routes in sensory effects remains poorly understood. The data reported by Genter et al. (1994) suggested that CYP2E1-mediated metabolism is involved in the olfactory toxicity of IDPN. Recent work from our laboratory has demonstrated that this P450 isoform is associated with cyanide release and acute lethality in mice exposed to cis-crotononitrile and allylnitrile but, unlike for other CYPs, not with the vestibular toxicity of these nitriles (Boadas-Vaello et al., 2007, 2009). Therefore, the lethal and vestibulotoxic effects of some nitriles appear to result from competing pathways of xenobiotic metabolism. Thus, we hypothesized that other nitriles might generate vestibulotoxic metabolites but have not been revealed to be vestibulotoxic due to the lethality associated with their simultaneous metabolism to cyanide. Identification of such nitriles may be facilitated by the absence of CYP2E1 and will help future modeling of structure-activity relationships. 
In the present study we evaluated nineteen nitriles for vestibular toxicity in wildtype and CYP2E1 knock-out mice (Lee et al., 1996). Because sex differences have been found in nitrile metabolism and toxicity in mice (Chanas et al., 2003; BoadasVaello et al., 2007), males and females were studied separately. The study used a new acute toxicity test protocol designed to facilitate the identification of the vestibular toxicity at sub-lethal doses by means of a systematic approach, while using a low number of animals per compound, sex, and strain, and simplifying the management of the animal colonies.

\section{METHODS}

\subsection{Chemicals and reagents}

The nitriles used are shown in Figure 1 and additional information is provided in Table 1. Cis- and trans-crotononitrile were separated by fractionated distillation from a commercially available racemic mixture (99\%, cis:trans ratio of approximately 60:40, Aldrich Quimica, Alcobendas, Spain), as previously described (Balbuena and Llorens, 2003); fractions with an isomeric purity greater than $97 \%$ (by ${ }^{1} \mathrm{H}-\mathrm{NMR}, 300 \mathrm{MHz}$, using $\mathrm{CDCl}_{3}$ as solvent, in a Varian Unity 300 spectrometer) were used in this study. Other nitriles were of commercial origin as listed in Table 1.

\subsection{Animals}

Animal care and use were in accordance with Acts 5/1995 and 214/1997 of the government of Catalonia (the Generalitat), and approved by the government's Commission on Animal Experimentation. CYP2E1-null mice (Lee et al., 1996) were obtained from a local colony established by breeding pairs generously donated by F.J. Gonzalez (US NIH, Bethesda, USA). Because the CYP2E1-null mice were derived from the 129/SV strain, 129S1/SvImJ mice, with a similar genetic background, were chosen as controls. A local colony of this strain was established by breeding pairs obtained from the Jackson Laboratory (Bar Harbor, ME, USA). After weaning, mice were housed two to four per cage in standard Macrolon cages $(28 \times 28 \times 15 \mathrm{~cm})$ with wood shavings as bedding and given standard diet pellets (Harlan Teklad Global Diet 2014) ad libitum.

\subsection{Dosing and experimental protocol}

Nitriles were administered po in $6 \mathrm{ml} / \mathrm{kg}$ of vehicle, as listed in Table 1 . The 
compounds were tested independently in male and female mice, and both sexes were assessed except in the cases of trans-3-dimethylaminoacrylonitrile, 3methylaminopropionitrile, and 3-hydroxypropionitrile, which were tested in males only. For each nitrile, one wild-type mouse (129S1) and one mouse with no CYP2E1 expression (CYP2E1-null) of each sex were exposed to an initial dose on day 0 . The initial dose was $1 \mathrm{mmol} / \mathrm{kg}$, or $0.25 \mathrm{mmol} / \mathrm{kg}$ if the data available in the literature indicated that the lethal dose was near or below $1 \mathrm{mmol} / \mathrm{kg}$. The animals were observed at least at $20 \mathrm{~min}, 1 \mathrm{~h}, 4 \mathrm{~h}, 1$ day, 2 days, 3 days, 4 days, and 7 days after dosing. Animals were rated for overall toxicity and killed if they reached the criteria of ethical limits of suffering. In terms of data analysis, animals killed on ethical grounds were considered equal to those presenting spontaneous death. If the animal died after the initial dose, a new animal was used to re-start the protocol with an initial dose of 1/8 of the former initial dose. The mice were also assessed for vestibular dysfunction at 3 and 7 days. On day 7, animals showing no toxicity, or only transient effects followed by recovery, were given a nitrile dose twice that of the previous dose. This was repeated at weekly intervals until overt toxicity became apparent or an upper limit of $64 \mathrm{mmol} / \mathrm{kg}$ was reached. In this case, two new animals of the same sex and strain were given the upper limit dose and observed for 14 days. This first part of the protocol is illustrated in Figure 2A.

When the first animal showed overt toxic effects (lethality, vestibular dysfunction or other overt toxicity), two additional animals from the same sex and strain were given the same dose (dose A), and observed as described above up to day 7 . Depending on the results observed, groups of three naïve animals were successively administered larger doses $(1.25 \mathrm{x} \mathrm{A}$, next $1.50 \mathrm{x} \mathrm{A}$, and so on, in the case of no toxicity or mild vestibular toxicity, defined as vestibular rating scores below 15), or smaller doses $(0.75 \mathrm{x} A$, in the case of overt toxicity, lethality or vestibular rating scores of 15 or more, then followed by $0.625 \times \mathrm{A}$ or $0.875 \mathrm{x} \mathrm{A}$ ). The dose steps thus evaluated were three linear increment steps between logarithmic $(2 \mathrm{x})$ increment steps, that is, for instance, $2.5 \mathrm{mmol} / \mathrm{kg}, 3.0 \mathrm{mmol} / \mathrm{kg}$, and $3.5 \mathrm{mmol} / \mathrm{kg}$ between $2.0 \mathrm{mmol} / \mathrm{kg}$ and 4.0 $\mathrm{mmol} / \mathrm{kg}$. The second part of the protocol is illustrated in Figure 2B.

To obtain histological evidence of the vestibular toxicity of trans-crotononitrile, 129S1 female mice were administered 0 or $6 \mathrm{mmol} / \mathrm{kg}$ of this nitrile, evaluated for vestibular function at 3, 7, and 21 days, and killed for histological analysis 5 weeks after dosing. 


\subsection{Behavioral analysis of vestibular function}

The disturbance of vestibular function was determined using a battery of behavioral tests initially developed for the rat (Llorens et al., 1993; Llorens and Rodríguez-Farré, 1997) and recently adapted to the mouse (Soler-Martín et al., 2007; Boadas-Vaello et al., 2007, 2009). Briefly, mice were placed for one minute in an open arena (a rat housing cage) and the experimenter rated the animals from 0 to 4 for circling, retropulsion, and abnormal head movements. Circling was defined as stereotyped circling ambulation. Retropulsion consisted of backward movement. Head bobbing consisted of intermittent extreme backward extension of the neck. The mice were then rated 0 to 4 for the tail-hang reflex, contact inhibition of the righting reflex, and air righting reflex tests. When lifted by the tail, normal mice exhibit a "landing" response consisting of forelimb extension. Mice with impaired vestibular function bend ventrally, sometimes "crawling" up towards their tails, thus tending towards occipital landing. For the contact inhibition of the righting reflex, mice were flipped supine on a horizontal surface and a rigid plastic board was lightly placed in contact with the soles of their feet. Healthy mice quickly right themselves, but vestibular-deficient mice lie on their back, with their feet up and "walk" with respect to the ventral surface. For the air righting reflex, the animals were dropped supine from a height of $10 \mathrm{~cm}$ onto a foam cushion. Normal mice are able to right themselves in the air whereas vestibular-deficient mice are not. A summary statistic was obtained by adding up the scores for all behavior patterns.

\subsection{Histology}

We examined surface preparations of the vestibular sensory epithelia using scanning electron microscopy (SEM), following standard procedures as described elsewhere (Llorens et al., 1993; Seoane et al., 2001; Soler-Martín et al., 2007). Briefly, the temporal bones were obtained and immediately immersed in ice-cold $2.5 \%$ glutaraldehyde in 0.1 M cacodylate buffer ( $\mathrm{pH} 7.2$ ), and the sensory epithelia from the inner ear were quickly dissected. The samples were fixed for $1.5 \mathrm{~h}$ in the same solution, post-fixed for $1 \mathrm{~h}$ in $1 \%$ osmium tetroxide in cacodylate buffer, dehydrated with increasing concentrations of ethanol up to $100 \%$, and dried in a critical-point dryer using liquid $\mathrm{CO}_{2}$. The dried sensory epithelia were coated with gold and observed in a Quanta-200 SEM (FEI Company, Hillsboro, OR, USA).

\section{RESULTS}


Figure 3 summarizes the main results of the study. For each nitrile, the doses inducing lethal and/or vestibular toxicity effects are indicated for both sexes and both strains of mice. To ease comparisons by sex or strain, four partial graphs are provided as supplementary Figures 1A to 1D. To ease data use, the data are provided in numerical format in supplementary Tables 1 and 2.

For several nitriles, lethal dose estimates were determined in both 129S1 (wild type) and CYP2E1-null strains as well as in both sexes. The lethal dose estimate was defined as the lowest dose causing death to two or three out of three animals; this included both spontaneous death and overt toxicity compelling euthanasia of the animal on ethical grounds. When vestibular toxicity was identified before maximal doses were reached, no lethal dose estimates were obtained (for example, in both sexes and strains with IDPN). In most cases, nine animals were used, but smaller and larger numbers were also used, which resulted in a mean of $8.5 \pm 0.3(\mathrm{X} \pm \mathrm{SE})$.

Large differences between strains in lethal dose estimates were found for some nitriles while other nitriles showed small differences. In all cases in which straindependent differences in lethal doses were recorded, the nitrile was more toxic in the wild-type 129S1 than in CYP2E1-null mice. The largest difference was recorded for 3hydroxybutyronitrile in male mice, with a lethal dose of $3 \mathrm{mmol} / \mathrm{kg}$ in $129 \mathrm{~S} 1$ mice and of $40 \mathrm{mmol} / \mathrm{kg}$ in CYP2E1-null males. In some cases, the effect of the strain appeared to depend on sex; for example, in the case of propionaldehyde cyanohydrin larger differences were recorded in male than in female mice.

We compared the relationship between the estimated lethal dose levels for male 129S1 mice in the present study with the LD50 data from the ChemIDplus Lite application as accessed from TOXNET (http://toxnet.nlm.nih.gov/index.html) or from the Safety Data Sheet provided by the supplier. Included in the analysis were oral mouse LD50 data for seven nitriles, intraperitoneal mouse LD50 data for two nitriles, and rat oral LD50 data for three nitriles. Excluded from the analysis were five compounds for which no data were available in these sources, as well as two nitriles for which we had obtained no lethal dose estimates in 129S1 mice because vestibular toxicity was found before lethality occurred. As shown in Figure 4, a good correlation was found $(r=0.96, p<0.0001)$ with a single outlier, acetone cyanohydrin. For this nitrile we obtained an estimated lethal dose of $0.375 \mathrm{mmol} / \mathrm{kg}$, while a figure of $1.9 \mathrm{mg} / \mathrm{kg}$, corresponding to $0.022 \mathrm{mmol} / \mathrm{kg}$, is listed as oral mouse LD50 in the ChemIDplus Lite database. 
Vestibular toxicity was identified for allylnitrile, cis-crotononitrile, cis-2pentenenitrile, trans-crotononitrile, and IDPN. In all cases, both male and female mice were affected, and in no case were the CYP2E1-null animals significantly protected against nitrile-induced vestibular toxicity. The largest difference among strains was found for IDPN. For this nitrile, a reduced sensitivity to vestibular toxicity was observed in 129S1 female compared with male mice, while no difference was apparent in CYP2E1-null mice.

The vestibular toxicity of trans-crotononitrile was confirmed by histological assessment. SEM imaging of vestibular sensory epithelia from mice exposed to transcrotononitrile and showing behavioral evidence of vestibular dysfunction revealed loss of hair bundles indicative of sensory cell degeneration, in comparison to the normal density of hair bundles observed in the control vestibular sensory epithelia (Figure 5).

\section{DISCUSSION}

Previous data from our laboratory have demonstrated that CYP2E1-mediated metabolism of allylnitrile and cis-crotononitrile results in cyanide release and acute lethality while a different CYP activity is probably involved in the vestibular toxicity of these nitriles (Boadas-Vaello et al., 2007; 2009). In the present study, the differential role of the CYP2E1 in the lethal and vestibulotoxic effects of nitriles was assessed for 17 additional nitriles.

In this study, wild type and CYP2E1-null animals were maintained as two separate colonies. These two colonies derive from a common origin (Lee et al., 1996) and are thus genetically similar, but the existence of strain differences not related to the presence or absence of the cyp2el gene cannot be directly ruled out. However, the role of CYP2E1 in the differences recorded in cyanide release and lethal effects have been corroborated previously (Boadas-Vaello et al., 2007, 2009). In addition, the fact that the two strains do differ in CYP2E1 activity has been ascertained (Boadas-Vaello et al., 2009), so the absence of differences between these strains indicates that the CYP2E1 activity does not have any influence on the measured parameter.

We designed a test protocol to assess the potential vestibular toxicity of the nitriles at acute doses up to maximal levels, allowing a sufficient assessment of sublethal doses but at the same time using a minimal number of animals per each nitrile, strain, and sex. The protocol allowed the desired evaluations to be carried out using a similarly low number of animals regardless of the dose at which the nitrile showed 
vestibular toxicity or lethality, and regardless of whether or not information was available on the toxicity of the tested nitrile. This was achieved through the repeated use of a single animal per nitrile, strain, and sex, exposed to increasing doses at weekly intervals. We selected these parameters because most low molecular weight nitriles have rapid clearance and limited capacity for accumulating effects, but 14-day intervals and/or the use of new animals could be included in this initial phase of the protocol in future studies.

The application of the test protocol produced lethal dose estimates for many of the tested nitriles. In five cases, no toxicity data were found in the databases, so the present may be the first available data for these compounds. In the remaining cases, our lethal dose estimations were in quite good agreement with the data available in the literature except for acetone cyanohydrin. For this nitrile, values are available that differ from the extremely low oral mouse LD50 value listed in the ChemIDplus Lite database. This database lists an oral LD50 value of $0.22 \mathrm{mmol} / \mathrm{kg}$ for the rat, and Willhite and Smith (1981) give an estimate of $0.1 \mathrm{mmol} / \mathrm{kg}$ for i.p. LD50 in the mouse, figures which are closer to our oral mouse estimation. The ChemIDplus Lite database lists an oral mouse LD50 value for cyanide of $0.12 \mathrm{mmol} / \mathrm{kg}$, and acute acetone cyanohydrin toxicity is probably mediated by cyanide release (Willhite and Smith, 1981), so it seems unlikely that an LD50 value 5.5 times lower than that of cyanide is more accurate than our estimation, which is three times higher than the cyanide value. An additional fact to be considered is that we prepared acetone cyanohydrin doses in acidified saline, so as to prevent degradation to cyanide before administration.

CYP2E1-null mice were protected against lethality induced by several of the nitriles evaluated. However, the study also identified several nitriles for which no apparent change in toxicity was associated with lack of CYP2E1. These data may be useful for modeling the role of this enzyme in nitrile bioactivation (Lewis et al., 1994). Also, these data may be useful if pharmacological inhibition of the CYP2E1 enzyme is considered to treat acute nitrile intoxication (Suhua et al., 2010). In relation to this possibility, it is worth pointing out that the increased survival rate in CYP2E1-null mice, when observed, was not associated with the emergence of vestibular toxicity or other apparent chronic neurologic toxicity.

The protocol was effective in detecting the vestibular toxicity of allylnitrile, ciscrotononitrile, cis-2-pentenenitrile, and IDPN. All these nitriles have been demonstrated to be ototoxic in rats and mice (Llorens et al., 1993; Balbuena and Llorens, 2001; 
Gagnaire et al., 2001; Balbuena and Llorens, 2003) after previous reports had shown their major effect on spontaneous behavior (Delay et al., 1954; Tanii et al., 1989a,b). For allylnitrile, $c i s$-crotononitrile and cis-2-pentenenitrile, six or nine animals per sex and strain were required. Instead, for IDPN, a compound known to induce vestibular toxicity at doses well below lethal doses (Llorens et al., 1993) only three animals per sex and strain were sufficient to identify this property and to indicate a higher susceptibility in male than in female mice in the wild-type strain. A similar sexdependent difference in susceptibility to IDPN has been documented in rats (Moser and Boyes, 1993).

Among the 15 nitriles evaluated for vestibular toxicity for which no previous evidence for this property was available, one was positive and 14 were negative. The fact that all the nitriles known to be ototoxic were effectively identified by our protocol supports the conclusion that none of the 14 nitriles yielding negative results in this study cause vestibular toxicity in the mouse following acute exposure. This result implies that vestibular toxicity is not a common toxic effect of the nitrile group that remains masked by lethality, but it is rather an effect that depends on strict structural requirements. Behavioral data by Tanii et al. (1989a) also support this conclusion.

The identification of trans-crotononitrile as a vestibulotoxic nitrile in this species is a remarkable finding, because this nitrile causes no vestibular toxicity in the rat (Balbuena and Llorens, 2003; Boadas-Vaello et al., 2005); in the latter species, trans-crotononitrile causes a selective degeneration of a number of neuronal populations in the central nervous system, including the inferior olive and the piriform cortex (Seoane et al., 2005; Boadas-Vaello et al., 2005). Nitrile neurotoxicity thus depends on the species considered. Given the evidence available for a role in biotransformation in the vestibular toxicity of the nitriles (Boadas-Vaello et al., 2007, 2009), we hypothesize that differences in trans-crotononitrile metabolism between species are likely to be the cause of these differences in toxic effects.

The five ototoxic nitriles include one compound, cis-2-pentenenitrile, with a relevant industrial role, as it is generated during the synthesis of nylon (DeVito, 2007). The vestibulotoxic doses of $c i s-2$-pentenenitrile were close to the known lethal doses, so current safety factors are likely to be adequate to prevent workers from the acute ototoxic effects of this nitrile. However, ototoxic compounds may act synergistically with noise to induce hearing loss (Fechter, 2004), so the possibility that this nitrile promotes noise-induced hearing loss at lower doses deserves further investigation. The 
other four ototoxic nitriles have less relevant industrial presence, but some are natural compounds. Allylnitrile is a common secondary metabolite in many cruciferous vegetables, although the vestibulotoxic doses in mice have been demonstrated to be well above those humans are likely to be exposed to (Tanii et al., 2004). Crotononitrile (isomer not identified) has been found along with allylnitrile and other nitriles in honeys (Soria et al., 2008), but the human exposure from natural sources has not been evaluated.

No bioactivating role for CYP2E1-mediated metabolism was identified for any of the five ototoxic nitriles, while the CYP2E1-null condition was associated with a slight increase in susceptibility to this effect in females exposed to IDPN. On the basis of theoretical and modeling studies of CYP-mediated alpha-hydroxylation of nitriles (Grogan et al., 1992; Lewis et al., 1994), data on the role of cyanide in nitrile acute toxicity (Willhite and Smith, 1981; Tanii and Hashimoto, 1984, 1986; Benz and Nerland, 2005; ElHadri et al., 2005), and our previous data on the differential role of CYP2E1 in the lethal and vestibulotoxic effects of cis-crotononitrile and allylnitrile (Boadas-Vaello et al., 2007, 2009), it is likely that the differences recorded in lethal dose depend on differences in cyanide release through formation of a cyanohydrin (alpha-hydroxynitrile) intermediate. At the same time, all this information argues strongly against the possibility that either cyanide or cyanohydrin metabolites are the circulating active metabolites in nitrile ototoxicity.

At present, the mechanisms for the audiovestibular toxicity of nitriles remain unidentified. Depletion of glutathione stores has been shown to be a major consequence of acrylonitrile exposure (Benz et al., 1997; Khan et al., 2009), and this has been associated with a potentiation of noise-induced hearing loss in rats exposed to this nitrile (Fechter et al., 2003; Pouyatos et al., 2007). However, acrylonitrile was not found to induce permanent hearing loss (Fechter et al., 2003; Pouyatos et al., 2007) or significant vestibular toxicity (Khan et al., 2009), even though it causes in several brain regions larger depletions of reduced glutathione levels than IDPN does (Khan et al., 2009). Thus, although the ototoxic effects of nitriles could involve depletion of antioxidant defenses, such a mechanism may not be the main reason for the selective effect of some nitriles on the audiovestibular system.

In conclusion, toxicity data were obtained for 19 nitriles both in wild type and in CYP2E1-null mice. Five of these nitriles were found to have significant vestibular toxicity, including previously identified ototoxic nitriles, and trans-crotononitrile, a 
compound with a different profile of neurotoxic effects in the rat. Thus, only a subset of nitriles is ototoxic and there are species-dependent differences in susceptibility to this effect. We also conclude that CYP2E1 activity has no bioactivation role in the ototoxic effects of nitriles, although it does have this role for the acute lethality of several of these nitriles. Taken together, these and previous results indicate that cyanohydrin metabolites are unlikely to be the circulating active metabolites in nitrile ototoxicity. 


\section{ACKNOWLEDGEMENTS}

We thank Frank J. Gonzalez (NIH, Bethesda, USA) for generously providing the CYP2E1-null mice, Angel Messeguer (CSIC, Barcelona, Spain) for help with the distillation of the crotononitrile isomers and Pere Boadas-Vaello for his contributions to preliminary work. We also thank our student Xavier Farré for his assistance in some of the experiments. This work was supported by the Ministry of Science and Innovation (Spain) / Fondo Europeo de Desarrollo Regional (European Union) [grant number BFU2009-06945] and by the Generalitat de Catalunya [grant number 2009 SGR 1059]. The SEM studies were performed at the Serveis Científico-Tècnics (ScientificTechnical Services) of the University of Barcelona. 


\section{REFERENCES}

Balbuena, E., Llorens, J., 2001. Behavioural disturbances and sensory pathology following allylnitrile exposure in rats. Brain Res. 904, 298-306.

Balbuena, E., Llorens, J., 2003. Comparison of cis- and trans-crotononitrile effects in the rat reveals specificity in the neurotoxic properties of nitrile isomers. Toxicol. Appl. Pharmacol. 187, 89-100.

Benz, F.W., Nerland, D.E., 2005. Effect of cytochrome P450 inhibitors and anticonvulsants on the acute toxicity of acrylonitrile. Arch. Toxicol. 79, 610-614.

Benz, F.W., Nerland, D.E., Li, J., Corbett, D., 1997. Dose dependence of covalent binding of acrylonitrile to tissue protein and globin in rats. Fundam. Appl. Toxicol. 36: 149-156.

Boadas-Vaello, P., Riera, J., Llorens, J., 2005. Behavioral and pathological effects in the rat define two groups of neurotoxic nitriles. Toxicol. Sci. 88, 456-466.

Boadas-Vaello P., Jover, E., Díez-Padrisa, N., Bayona, J.M., Llorens J., 2007. Differential role of CYP2E1-mediated metabolism in the lethal and vestibulotoxic effects of ciscrotononitrile in the mouse. Toxicol. Appl. Pharmacol. 225, 310-317.

Boadas-Vaello, P., Jover, E., Llorens, J., Bayona, J.M., 2008. Determination of cyanide and volatile alkylnitriles in whole blood by headspace solid-phase microextraction and gas chromatography with nitrogen phosphorus detection. J. Chromatogr. B 870, 17-21.

Boadas-Vaello, P., Jover, E., Saldaña-Ruíz, S., Soler-Martín, C., Chabbert, C., Bayona, J.M. Llorens, J., 2009. Allylnitrile metabolism by CYP2E1 and other CYPs leads to distinct lethal and vestibulotoxic effects in the mouse. Toxicol. Sci. 107, 461-472

Chanas, B., Wang, H., Ghanayem, B.I., 2003. Differential metabolism of acrylonitrile to cyanide is responsible for the greater sensitivity of male vs female mice: role of CYP2E1 and epoxide hydrolases. Toxicol. Appl. Pharmacol. 193, 293-302.

Crofton, K.M., Knight, T., 1991. Auditory deficits and motor dysfunction following iminodipropionitrile administration in the rat. Neurotoxicol. Teratol. 13, 575-581.

Crofton, K.M., Janssen, R., Prazma, J., Pulver, S., Barone, Jr.S., 1994. The ototoxicity of 3,3'-iminodipropionitrile: Functional and morphological evidence of cochlear damage. Hear. Res. 80, 129-140.

Delay, J., Pichot, P., Thuillier, J. Marquiset, J. P., 1952. Action de l'aminodipropionitrile sur le comportement moteur de la souris blanche. C. R. Soc. Biol. 146, 533-534.

DeVito, S.C., 1996. Designing safer nitriles. In: Designing safer chemicals (DeVito, S.C., Garrett, R.L., Eds.). pp. 194-223. American Chemical Society, Washington DC,.

El Hadri, L., Chanas, B., Ghanayem, B.I., 2005. Comparative metabolism of methacrylonitrile and acrylonitrile to cyanide using cytochrome P4502E1 and microsomal epoxide hydrolase-null mice. Toxicol. Appl. Pharmacol. 205,116-125.

Fechter, L.D., 2004. Promotion of noise-induced hearing loss by chemical contaminants. J. Toxicol. Environ. Health. A. 67: 727-740.

Fechter, L.D., Klis, S.F.L., Shirwany, N.A., Moore, T.G., Rao, D.B. 2003. Acrylonitrile produces transient cochlear function loss and potentiates permanent noise-induced hearing loss. Toxicol. Sci. 75: 117-123.

Gagnaire, F., Marignac, B., Ban, M., Langlais, C., 2001. The ototoxic effects induced in rats by treatment for 12 weeks with 2-butenenitrile, 3-butenenitrile and cis-2pentenenitrile. Pharmacol. Toxicol. 88, 126-134.

Ghanayem, B.I., Sanders, J.M., Chanas, B., Burka, L.T., Gonzalez, F.J., 1999. Role of cytochrome P-450 2E1 in methacrylonitrile metabolism and disposition. J. Pharmacol. Exp. Ther. 289, 1054-1059. 
Genter, M.B., Llorens, J., O'Callaghan, J.P., Peele, D.B., Morgan, K.T., Crofton, K.M., 1992. Olfactory toxicity of $\beta, \beta^{\prime}$-iminodipropionitrile (IDPN) in the rat. J. Pharmacol. Exp. Ther. 263, 1432-1439.

Genter, M.B., Deamer, N.J., Cao, Y., Levi, P.E., 1994. Effects of P450 inhibition and induction on the olfactory toxicity of $\beta, \beta^{\prime}$-iminodipropionitrile (IDPN) in the rat. J. Biochem. Toxicol. 9, 31-39.

Grogan, J., DeVito, S.C., Pearlman, R.S. Korzekwa, K.R., 1992. Modeling cyanide release from nitriles : prediction of cytochrome $\mathrm{P} 450$ mediated acute nitrile toxicity. Chem. Res. Toxicol. 5, 548-552.

Khan, H.A., Alhomida, A.S., Arif, I.A., 2009 Neurovestibular toxicities of acrylonitrile and iminodipropionitrile in rats: a comparative evaluation of putative mechanisms and target sites. Toxicol. Sci. 109: 124-131.

Lee, S.S., Buters, J.T., Pineau, T., Fernandez-Salguero, P., Gonzalez, F.J., 1996. Role of CYP2E1 in the hepatotoxicity of acetaminophen. J. Biol. Chem. 271, 12063-12067.

Lewis, D.F.V., Ioannides, C., Parke, D.V., 1994. Interaction of a series of nitriles with the alcohol-inducible isoform of P450: computer analysis of structure-activity relationships. Xenobiotica 24, 401-408.

Llorens, J., Demêmes, D., Sans, A., 1993. The behavioral syndrome caused by 3,3'iminodipropionitrile and related nitriles in the rat is associated with degeneration of the vestibular sensory hair cells. Toxicol. Appl. Pharmacol. 123, 199-210.

Llorens, J., Rodríguez-Farré, E., 1997. Comparison of behavioral, vestibular, and axonal effects of subchronic IDPN in the rat. Neurotoxicol. Teratol. 19, 117-127.

Llorens, J., Aguiló, A., Rodríguez-Farré, E., 1998. Behavioral disturbances and vestibular pathology following crotonitrile exposure in rats. J. Peripher. Nerv. Syst. 3, 189-196.

Llorens, J., Soler-Martín, C., Saldaña-Ruíz, S., Cutillas, B., Ambrosio, S., BoadasVaello, P., 2011. A new unifying hypothesis for lathyrism, konzo and tropical ataxic neuropathy: nitriles are the causative agents. Food Chem. Toxicol. 49, 563-570.

Moser, V.C. Boyes, W.K., 1993. Prolonged neurobehavioral and visual effects of shortterm exposure to 3,3'-iminodipropionitrile (IDPN) in rats. Fundam. Appl. Toxicol. $21,277-290$

Ohkawa, H., Ohkawa, R., Yamamoto, I., Casida, J.E., 1972. Enzymatic mechanisms and toxicological significance of hydrogen cyanide liberation from various organothiocyanates and organonitriles in mice and houseflies. Pest. Biochem. Physiol., 2, 95-112.

Pouyatos, B., Gearhart, C., Nelson-Miller, A., Fulton, S., Fechter, L. 2007. Oxidative stress pathways in the potentiation of noise-induced hearing loss by acrylonitrile. Hear. Res. 224: 61-74.

Seoane, A., Apps, R., Balbuena, E., Herrero, L., Llorens, J., 2005. Differential effects of trans-crotononitrile and 3-acetylpyridine on inferior olive integrity and behavioural performance in the rat. Eur. J. Neurosci. 22, 880-894.

Seoane, A., Demêmes, D., Llorens, J., 2001. Relationship between insult intensity and mode of hair cell loss in the vestibular system of rats exposed to 3,3'iminodipropionitrile. J. Comp. Neurol. 439, 385-399.

Silver, E.H., Kuttab, S.H., Hasan, T., Hassan, M., 1982. Structural considerations in the metabolism of nitriles to cyanide in vivo. Drug Metab. Disp. 10, 495-498.

Soler-Martín, C., Diez-Padrisa, N., Boadas-Vaello, P., Llorens, J., 2007. Behavioral disturbances and hair cell loss in the inner ear following nitrile exposure in mice, guinea pigs, and frogs. Toxicol. Sci. 96, 123-132. 
Soria, A.C., Martínez-Castro, I., de Lorenzo, C., Sanz, J. 2008. Occurrence of nitriles in Taraxacum labelled honeys. Food Chem. 107: 439-443.

Suhua, W., Rongzhu, L., Wenrong, X., Guangwei, X., Xiaowu, Z., Shizhong, W., Ye, Z., Fangan, H., Aschner, M. 2010 Induction or inhibition of cytochrome P450 2E1 modifies the acute toxicity of acrylonitrile in rats: biochemical evidence. Arch Toxicol. 84: 461-469.

Tanii, H., Hashimoto, K., 1984. Studies on the mechanism of acute toxicity of nitriles in mice. Arch. Toxicol. 55, 47-54.

Tanii, H., Hashimoto, K., 1986. Influence of ethanol on the invivo and in vitro metabolism of nitriles in mice. Arch. Toxicol. 58, 171-176.

Tanii, H., Hayashi, M., Hashimoto, K., 1989a. Nitrile-induced behavioral abnormalities in mice. Neurotoxicology 10, 157-165.

Tanii, H., Kurosaka, Y., Hayashi, M., Hashimoto, K., 1989b. Allylnitrile: a compound which induces long-term dyskinesia in mice following a single administration. Exp. Neurol. 103, 64-67.

Tanii, H., Takayasu, T., Higashi, T., Leng, S., Saijoh, K., 2004. Allylnitrile: generation from cruciferous vegetables and behavioral effects on mice of repeated exposure. Food Chem. Toxicol. 42: 453-458.

Wang, H., Chanas, B., Ghanayem, B.I., 2002. Cytochrome P450 2E1 (CYP2E1) is essential for acrylonitrile metabolism to cyanide: comparative studies using CYP2E1-null and wild-type mice. Drug Metab. Dispos. 30, 911-917.

Willhite, C.C., Smith, R.P., 1981. The role of cyanide liberation in the acute toxicity of aliphatic nitriles. Toxicol. Appl. Pharmacol. 59, 589-602. 


\section{FIGURE CAPTIONS:}

Figure 1. Chemical structure of the 19 nitriles evaluated in the present study.

Figure 2. Test protocol used to evaluate the vestibular toxicity of nitriles at doses up to lethal levels using a minimal number of animals per nitrile, sex and strain. The schema is presented in two halves. The diagram in A was first followed until a dose (DA or DB) was selected to start the part of the protocol schematized in B.

Figure 3. Doses causing lethality to 2 or 3 out of 3 mice, or significant vestibular dysfunction (as assessed by a specific behavioral test battery), in CYP2E1-null and wild-type (129S1) mice. M: male. F: female. Numbers in parentheses indicate the total number of animals used for each nitrile and sex, in both strains. N.D.: not determined.

Figure 4. Relationship between the available LD50 data and our lethal dose estimates in wild type males, for the 11 nitriles for which both values were available. The line indicates identical values.

Figure 5. Effects of trans-crotononitrile on the vestibular sensory epithelia of female 129S1 mice, as observed by scanning electron microscopy 5 weeks after exposure. (A) Control crista. Note the dense distribution of hair bundles over the surface of the sensory epithelium. (B) Higher magnification of the control crista in A. The arrow points to a hair bundle corresponding to a single hair cell. Note the close proximity of hair cells, which are known to be separated by a single supporting cell in distance. (C) Crista of a 129S1 female mouse treated with 6 $\mathrm{mmol} / \mathrm{kg}$ of trans-crotononitrile displaying a significant loss of vestibular function (vestibular rating score at day 3 was 17), and killed 5 weeks after dosing. Note the lack of hair cell bundles in the epithelium, particularly in the apical part (arrow). (D) Higher magnification of the crista in C. Very few hair bundles (arrows) remain in this severely affected area, and many supporting cells can be recognized between these few hair cells. Scale bars: $100 \mu \mathrm{m}$ in A and $\mathrm{C}, 10 \mu \mathrm{m}$ in $\mathrm{B}$ and $\mathrm{D}$. 


\section{CAPTIONS FOR SUPPLEMENTARY FIGURES}

Supplementary Figure 1. Doses causing lethality to 2 or 3 out of 3 mice, or significant vestibular dysfunction (as assessed by a specific behavioral test battery) in mice. The data are the same as those presented in main Figure 3, shown here in blocs to facilitate pair-wise comparisons. A. Data from 129S1 and CYP2E1-null male mice. B. Data from 129S1 and CYP2E1-null female mice. C. Data from male and female 129S1 mice. D. Data from male and female CYP2E1-null mice. Numbers in parentheses indicate the number of animals used for each nitrile and group. 
Figure 1

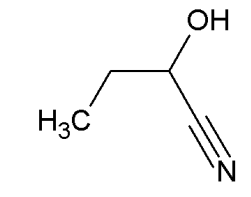

propionaldehyde cyanohydrin

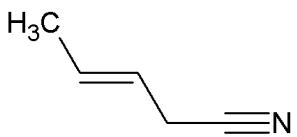

trans-3-pentenenitrile<smiles>CC/C=C\C#N</smiles>

cis-2-pentenenitrile

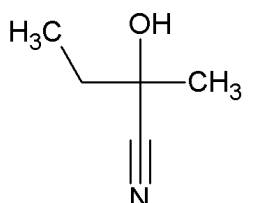

butanone cyanohydrin

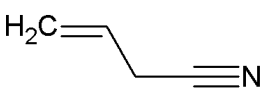

allyInitrile<smiles>CC(O)CC#N</smiles>

3-hydroxybutyronitrile

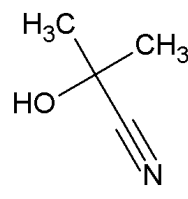

acetone

cyanohydrin

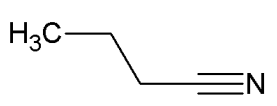

butyronitrile<smiles>CC(C)C#N</smiles>

isobutyronitrile<smiles>C/C(N)=C/C#N</smiles>

3-aminocrotononitrile cis-crotononitrile

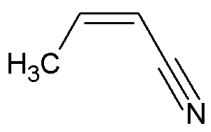

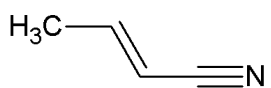

trans-crotononitrile

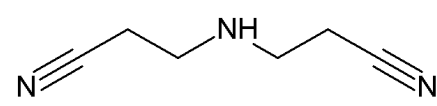

3,3'-iminodipropionitrile (IDPN)<smiles>CN(C)/C=C/C#N</smiles>

trans-3-dimethylaminoacrylonitrile

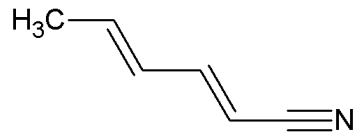

hexadienenitrile

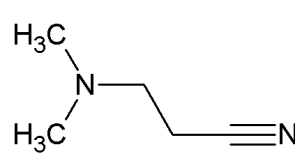

3-dimethylaminopropionitrile<smiles>CNCCC#N</smiles>

3-methylaminopropionitrile<smiles>N#CCCO</smiles>

3-hydroxypropionitrile 
Figure 2

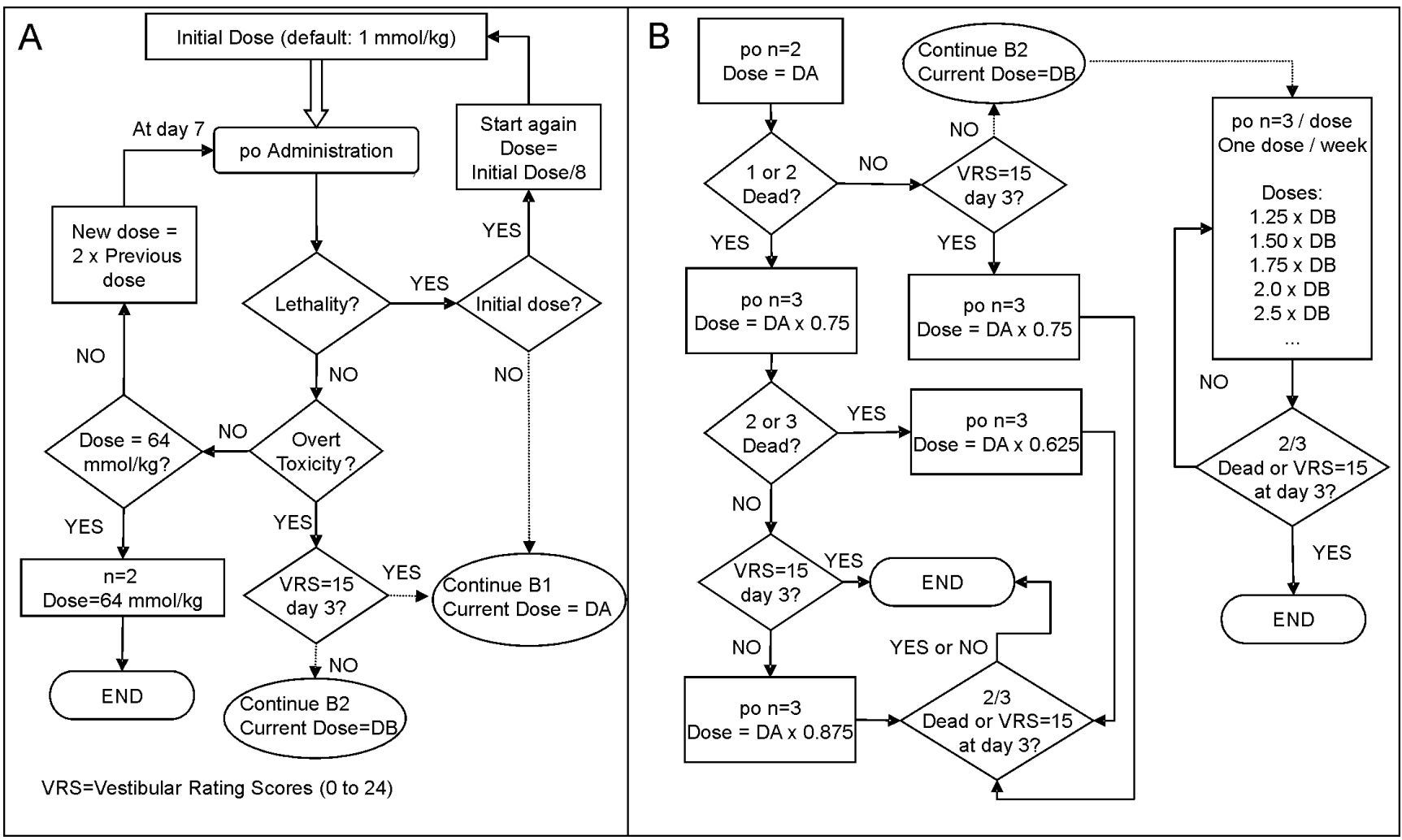


Wild-type (129S1) vs. CYP2E1-null mice (males and females)

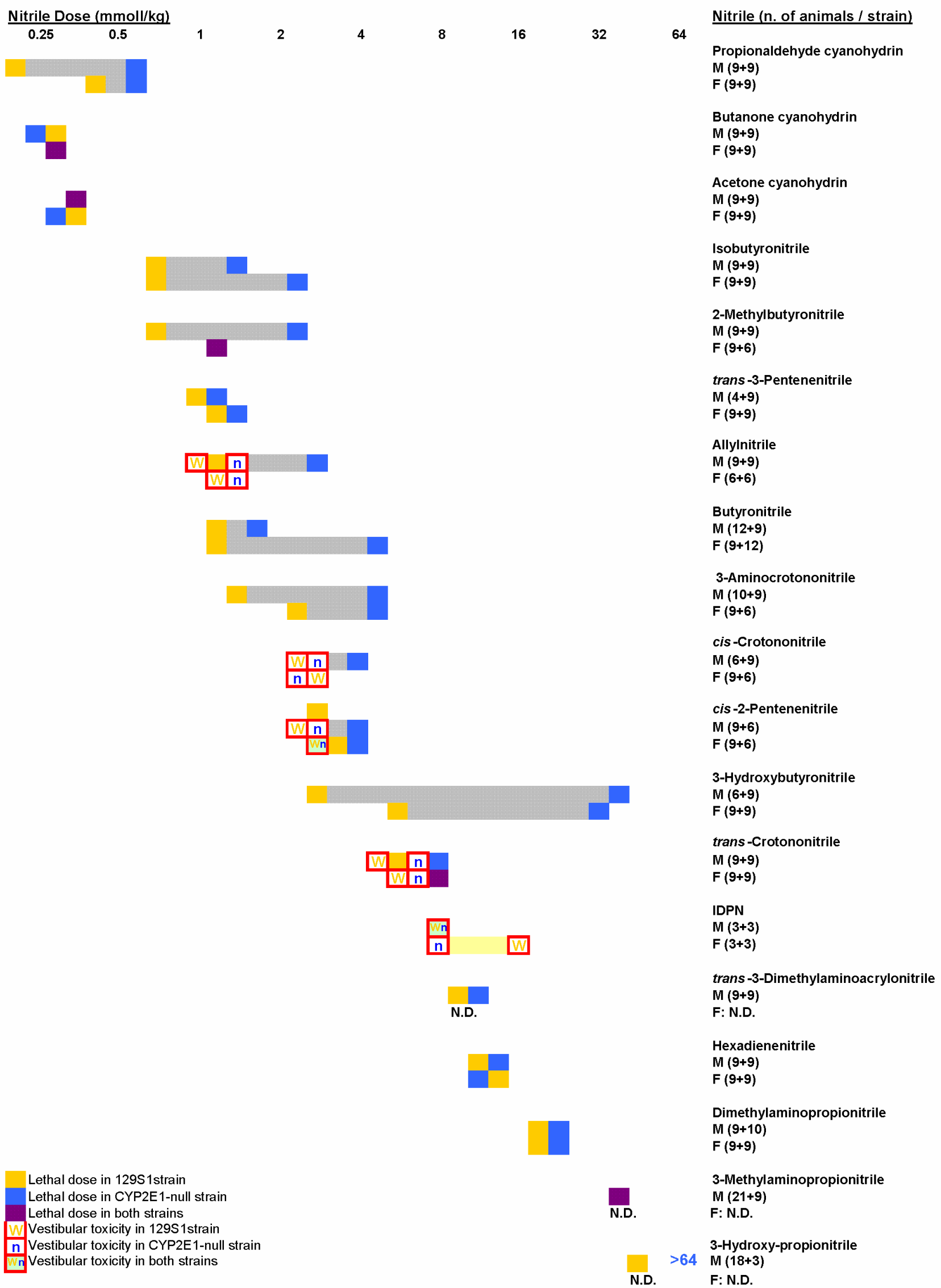


Figure 4

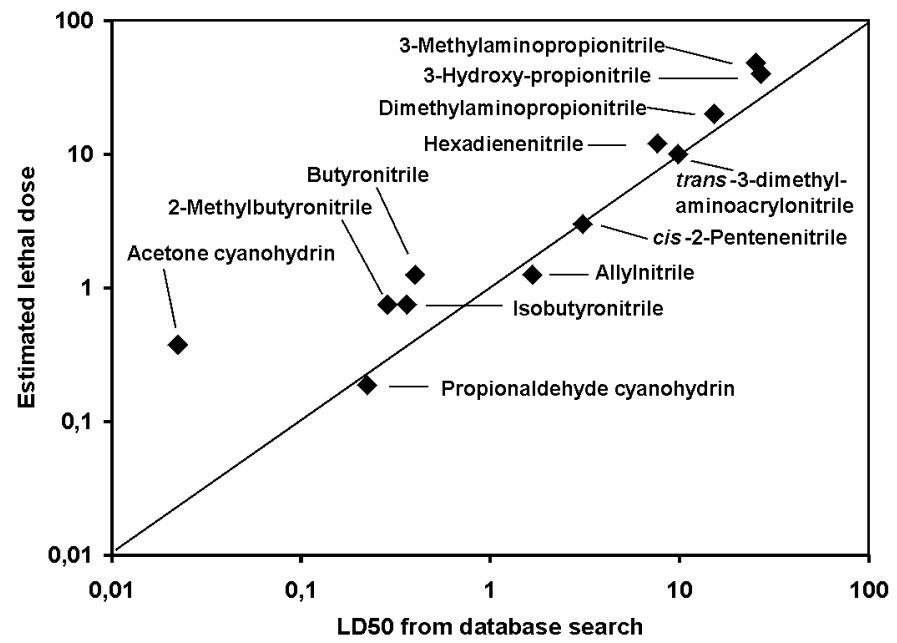

Figure 5
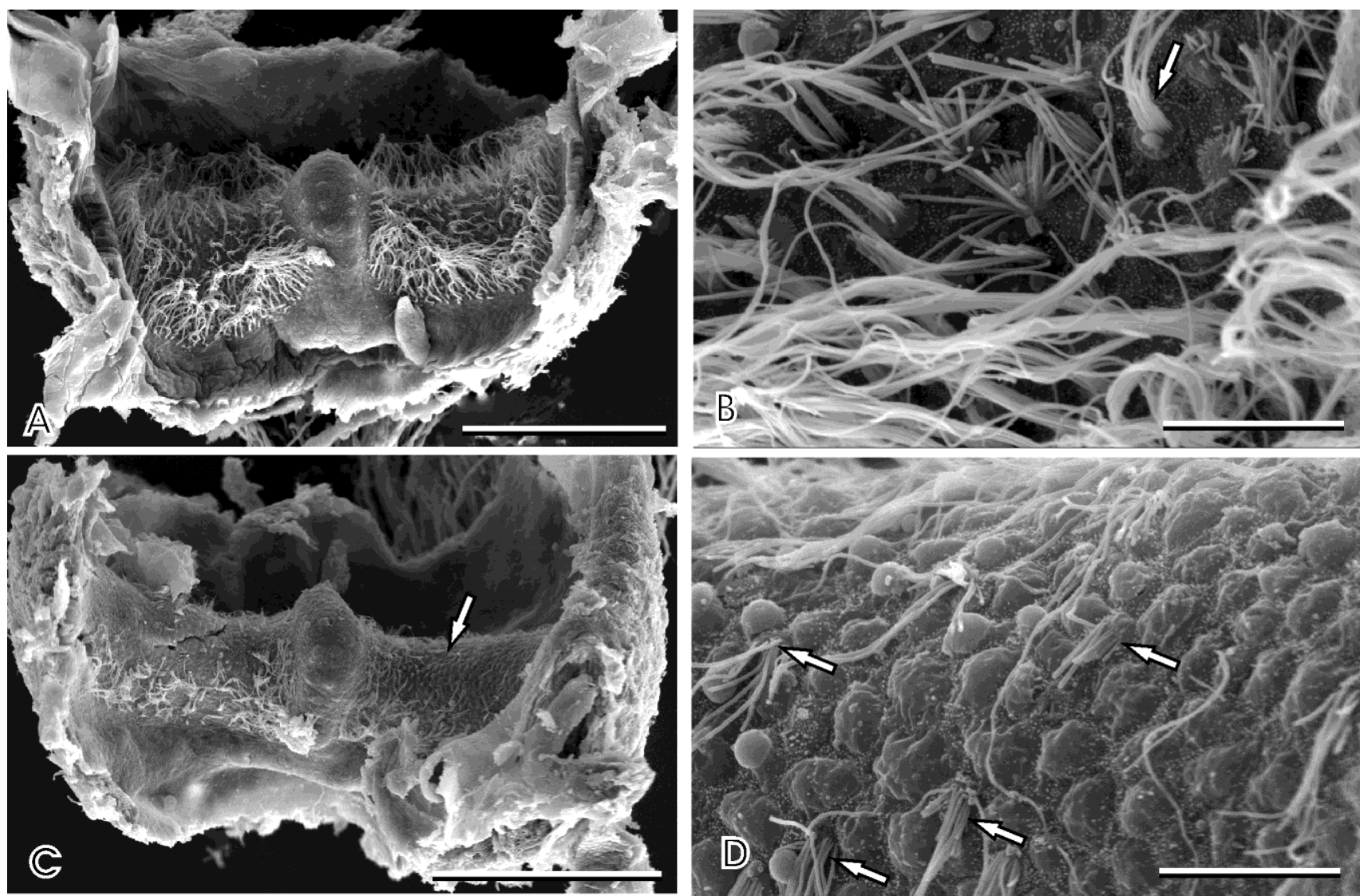


\section{CONFLICT OF INTEREST STATEMENT}

The authors declare that there are no conflicts of interest. 